\title{
Presidential Message
}

One hundred and fifty years of psychiatry in Britain and 20 years of the Royal College of Psychiatrists! The Association of Medical Officers of Asylums and Hospitals for the Insane was established in July 1841 in Gloucester and by 1855 had 121 ordinary members and two honorary members. It changed its name to the Medico-Psychological Association in 1865 and received its Royal Charter of Incorporation to become the Royal Medico-Psychological Association in 1926. In 1970, the final year of the Association, there were 3,823 ordinary members, 32 honorary, 61 corresponding, and 79 associate members $(3,995)$. Now, in 1991, we have 1,563 fellows, 5,061 members, 75 honorary fellows, 877 inceptors and 349 in other categories $(7,925)$.

The supplementary charter of 1971 allowed the association to become a Royal College, and in June 1971 the British Medical Journal, in a leading article, wrote:

"Its elevation to the status of a royal college gives fitting expression to the importance that psychiatry has attained as an integral part of medicine and reflects the confidence of the whole medical profession in those who are to become its Fellows and Members to maintain the prestige with which it is now endowed. Prestige, however, is a fickle mistress who can be lost as easily as she can be won. As well as offering encouragement to research and education in its specialty the Royal College of Psychiatrists would do well to take on the responsibility of trying to improve the conditions of some of the institutions in which psychiatric patients are being treated."

It went on to state "the standards of psychiatric practice at all levels must be improved so that the patients themselves are the beneficiaries". It welcomed the proliferation of chairs of psychiatry in British universities but emphasised, as prerequisites for good training, the need for rigorous standards for accreditation of psychiatric hospitals and the need for a searching membership examination.

How much progress has been made in achieving these objectives? The Membership examination has an acknowledged place among other medical postgraduate qualifications, and the major revision of 1987 has resulted in a sophisticated and dispassionate instrument, if expensive. The inspection of training in psychiatric hospitals and units carried out by the Central Approval Panel of the College and the Joint Committee on Higher Psychiatric Training has had the effect of raising standards, not only of training, but also of clinical practice, a valuable form of professional audit, so that our patients are the beneficiaries. It has constantly been the work of Council and the Court of Electors and their committees over the years to improve psychiatric practice, first and foremost in discussion with our Fellows and Members and then with the Department of Health and Government, with other related professional disciplines, with voluntary organisations and the general public.

The Anniversary year is a good opportunity not only to celebrate what has been achieved but also to try and make a more public statement. Mental illness still carries considerable stigma, with prejudice against the mentally ill, those who treat them, and even against support for research into causes. The College and especially the Public Education Committee hopes to use some of the public events of this year to try to alleviate this stigma. Ideas on how to do this would be very much welcomed.

The College is the official body for maintaining standards of practice in psychiatry for our two European nations, the United Kingdom and the Republic of Ireland. However, its influence extends much further. Many psychiatrists now practising in different parts of the world had their initial psychiatric training approved by, and were themselves examined by the College. Over the last few years the College has tried to encourage good practice in many countries where it is not able to exert direct authority.

Above all else there is clearly a need for the College to be active and effective in the future also. In the United Kingdom and Ireland new ways of practising psychiatry are being introduced; these could be summarised as working predominantly in the community rather than the institution, recognition of diverse needs of different groups of patients necessitating widely differing treatment settings, and the greater range of available methods of treatment we now have available. All this will result in a need for a considerable expansion in numbers of trained psychiatrists. Whether we are able to continue to provide an improved service to our patients will quite largely depend upon our success in providing postgraduate education of high quality, continuing medical education for trained psychiatrists so that their skills will be developed, and many further recruits to our specialty. There is a need for research into the basic causes and natural history of psychiatric disorders and also into evaluation of all the various types of treatment we now have and use.

Professor A. C. P. Sims

President

Royal College of Psychiatrists 